Article

\title{
Electrodeposition-Assisted Assembled Multilayer Films of Gold Nanoparticles and Glucose Oxidase onto Polypyrrole-Reduced Graphene Oxide Matrix and Their Electrocatalytic Activity toward Glucose
}

\author{
Baoyan $\mathrm{Wu}^{1}$, Shihua Hou ${ }^{2, *}$, Yongyong Xue ${ }^{1}$ and Zhan Chen ${ }^{3}$ \\ 1 MOE Key Laboratory of Laser Life Science \& Institute of Laser Life Science, College of Biophotonics, \\ South China Normal University, Guangzhou 510631, China; wubaoyan@scnu.edu.cn (B.W.); \\ xueyongyongscnu@163.com (Y.X.) \\ 2 School of Electronic and Information Engineering, South China University of Technology, \\ Guangzhou 510640, China \\ 3 College of Life Sciences, South China Normal University, Guangzhou 510631, China; \\ chenzhanscnu@163.com \\ * Correspondence: shhou@scut.edu.cn
}

Received: 26 October 2018; Accepted: 28 November 2018; Published: 1 December 2018

\begin{abstract}
The study reports a facile and eco-friendly approach for nanomaterial synthesis and enzyme immobilization. A corresponding glucose biosensor was fabricated by immobilizing the gold nanoparticles (AuNPs) and glucose oxidase (GOD) multilayer films onto the polypyrrole (PPy)/ reduced graphene oxide (RGO) modified glassy carbon electrode (GCE) via the electrodeposition and self-assembly. PPy and graphene oxide were first coated on the surface of a bare GCE by the electrodeposition. Then, AuNPs and GOD were alternately immobilized onto PPy-RGO/ GCE electrode using the electrodeposition of AuNPs and self-assembly of GOD to obtain AuNPs-GOD multilayer films. The resulting PPy-RGO-(AuNPs-GOD) $n$ /GCE biosensors were used to characterize and assess their electrocatalytic activity toward glucose using cyclic voltammetry and amperometry. The response current increased with the increased number of AuNPs-GOD layers, and the biosensor based on four layers of AuNPs-GOD showed the best performance. The PPy-RGO-(AuNPs-GOD) 4 /GCE electrode can detect glucose in a linear range from $0.2 \mathrm{mM}$ to $8 \mathrm{mM}$ with a good sensitivity of $0.89 \mu \mathrm{A} / \mathrm{mM}$, and a detection limit of $5.6 \mu \mathrm{M}(\mathrm{S} / \mathrm{N}=3)$. This study presents a promising eco-friendly biosensor platform with advantages of electrodeposition and self-assembly, and would be helpful for the future design of more complex electrochemical detection systems.
\end{abstract}

Keywords: polypyrrole; graphene; gold nanoparticles; electrodeposition; self-assembly; biosensor

\section{Introduction}

Diabetes is a growing public health problem and its complications, rather than the disease itself, are harmful for human body [1]. In medicine, diabetes is diagnosed mainly by detecting the concentration of glucose in the blood/urine [2]. Hence, glucose detection and quantification has received much attention. Until now, numerous techniques, such as chromatography [3,4], colorimetric $[5,6]$, and electrochemistry $[7,8]$ have been proposed for the determination of glucose. Although each glucose detection system has strengths and weaknesses, electrochemical methods have gained wide acceptance for analyses and are preferred over other techniques because of their simplicity, relatively low-costs, easy manufacturing and industrialization, and portable instruments [7-10]. Of the 
various glucose electrochemical detection methods, glucose oxidase modified electrodes play a crucial role in the detection of glucose $[7,9,11]$. Glucose oxidase is one of the most extensively researched enzymes for the construction of glucose enzymatic biosensors [12].

Enzyme immobilization matrix is a key component in biosensor fabrication. It can deeply influence the electrocatalytic activity of enzymatic sensors because of its improved recovery ability from the reaction systems for catalyst reuse as compared to homogeneously solubilized enzyme molecules [13-15]. With the continuous development of nanotechnology, close attention was taken in preparing the hybrid nanostructures as enzyme immobilization matrix [16-18]. For example, Wang et al., fabricated a transistor/glucose biosensor based on reduced graphene oxide (RGO) and polypyrrole (PPy) hybrid nanowires active layer [19]. Xue et al. used a ternary PPy/RGO/gold nanoparticles (AuNPs) nanocomposite to immobilize glucose oxidase [20]. The as-prepared biosensors exhibited good electrocatalytic property towards $\mathrm{O}_{2}$ or $\mathrm{H}_{2} \mathrm{O}_{2}$. PPy/RGO/AuNPs nanocomposites had already been applied in enzymatic biosensors and obtained satisfactory results.

PPy/RGO/AuNPs nanocomposites have typically been prepared by chemical or chemicalelectrochemical routes. Although these methods have advantages of large-scale and high yield, they frequently use excessive reducing agents resulting in contaminated nanocomposites, as well as enzyme denaturation and inactivation [21-23]. Recently, we reported a facile PPy/RGO/AuNPs fabrication on a glassy carbon electrode by drop-casting and electrodeposition consisting of the electrooxidation of pyrrole monomer and simultaneous electroreduction of graphene oxide and auric ions $\left(\mathrm{Au}^{3+}\right)$ in aqueous solution [24]. Despite the facile eco-friendly synthesis method, this work still suffers from film thickness side effects, because the drop-casting method lack control over film thickness [25].

Enzyme immobilization method is another critical process in enzymatic biosensor development. The immobilization of enzymes onto the electrode not only influences enzyme activity, but can also maintain the structural integrity of the enzyme for longer, which plays an important role in the overall performance of enzymatic biosensors [26,27]. Layer-by-layer (LBL) self-assembly has been extensively studied and proved. LBL assembly is a versatile approach to construct various biosensors with some obvious advantages owing to its operational controllability and simplicity [28-31]. It is important to note that the representation of the LBL assembly as a multilayer build-up based on a variety of interaction, including electrostatic attraction, hydrophobic attraction, covalent bonding, hydrogen bonding, and host-guest et al. [32,33]. More importantly, LBL assembly can enhance the sensitivity of the biosensor. Xue et al., built a graphene-gold nanorod hybrid architecture via LBL for electrochemical biosensors, which exhibited the highest sensitivity compared to the graphene oxide, cysteine-graphene oxide and graphene-gold nanorod coated electrodes [34]. Voelcker et al., reported that an electrochemical immune-sensor, prepared by self-assembly of peptides, afforded higher sensitivities for cardiac troponin I than those prepared by the chemisorption of alkane thiolated compounds [35].

Influenced by previous studies, this study focused on proposing a facile and environmentally friendly approach for PPy/RGO/AuNPs synthesis and glucose oxidase immobilization. The as-obtained amperometric glucose biosensor, based on the novel enzyme immobilization matrix, consisted of the electrodeposition-assisted assembled multilayer films of AuNPs-GOD and the electrodeposited PPy-RGO film. The amperometric glucose biosensor was developed and characterized by cyclic voltammetry and amperometry.

\section{Materials and Methods}

\subsection{Chemicals}

Glucose Oxidase from Aspergillus niger (GOD, EC 1.1.3.4, 100-250 U/mg) was purchased from Sigma-Aldrich Co. (Saint Louis, MO, USA). Graphene oxide (GO, $1 \mathrm{mg} / \mathrm{mL}$, solvent: water) was purchased from Xianfeng NANO material Tech Co. Ltd. (Nanjing, China). $\mathrm{HAuCl}_{4} \cdot 4 \mathrm{H}_{2} \mathrm{O}$ and 
pyrrole monomer were purchased from J\&K Scientific Ltd. (Beijing, China). Glucose, ascorbic acid, 4-acetamidophenol and uric acid were purchased from Aladdin Industrial Inc (Shanghai, China). Phosphate-buffered saline (0.1 M PBS, pH 7.0) buffer was employed as a supporting electrolyte. All electrochemical experiments were performed in PBS at room temperature, approximately $25^{\circ} \mathrm{C}$.

\subsection{Apparatus and Measurements}

Electrochemical measurements were carried out with $\mathrm{CHI} 800 \mathrm{C}$ electrochemical analyzer (Chen Hua Instruments, Shanghai, China) with a conventional three-electrode system, in which a glassy carbon electrode (GCE), a saturated calomel electrode (SCE) and a platinum wire electrode served as the working, reference, and auxiliary electrodes, respectively. The surface morphological features of PPy-GO and PPy-RGO-AuNPs were characterized using ZEISS Ultra 55 scanning electron microscopy (Carl Zeiss, Oberkochen, Germany).

\subsection{Configuration of the Amperometric Glucose Biosensor}

PPy-RGO-(AuNPs-GOD) $\mathrm{n} / \mathrm{GCE}$ was prepared according to the following steps:

Step 1: The bare GCE electrode was polished with chamois leather containing $0.05 \mu \mathrm{m}$ alumina slurry, rinsed thoroughly with water, sonicated in ethanol, and dried at room temperature.

Step 2: GO $(0.5 \mathrm{mg} / \mathrm{mL})$ were sonicated in pyrrole monomer solution $(0.3 \mathrm{M})$, centrifuged at $10,000 \mathrm{rpm}$ for $10 \mathrm{~min}$, and collected the supernatant. Then, the cleaned bare GCE was immersed into the supernatant, and a continuous cyclic voltammetric sweep of 10 cycles with potential ranging from $0 \mathrm{~V}$ to $0.8 \mathrm{~V}$ versus SCE was performed at a scan rate of $25 \mathrm{mV} / \mathrm{s}$ for the electrooxidation of pyrrole monomer and simultaneous immobilization of polypyrrole (PPy) and GO onto the electrode surface. The as-obtained electrode was regard as PPy-GO/GCE.

Step 3: PPy-GO/GCE was immersed into PBS containing $6.5 \mathrm{mM} \mathrm{HAuCl}_{4} \cdot 4 \mathrm{H}_{2} \mathrm{O}$. Then, a continuous cyclic voltammetric sweep of 6 cycles with potential ranging from $0 \mathrm{~V}$ to $-1.5 \mathrm{~V}$ versus SCE was performed at a scan rate of $25 \mathrm{mV} / \mathrm{s}$ to ensure the simultaneous electroreduction of both $\mathrm{GO}$ and $\mathrm{HAuCl}_{4}$ on the PPy-GO/GCE surface, which was regarded as PPy-RGO-AuNPs/GCE electrode.

Step 4: PPy-RGO-AuNPs/GCE was immersed in GOD $(2 \mathrm{mg} / \mathrm{mL})$ for 6 hours at $4{ }^{\circ} \mathrm{C}$ to immobilize GOD, and then thoroughly rinsed with PBS for dissociating the weak adsorption, which was regarded as the one layer of AuNPs-GOD multilayer films modified PPy-RGO/GCE electrode, PPy-RGO-(AuNPs-GOD) 1 /GCE.

Step 5: The different layers of multilayer films (AuNPs-GOD) $n$ modified PPy-RGO/GCE electrodes, PPy-RGO-(AuNPs-GOD) $)_{n}$ GCE were obtained by repeating $(n-1)$ times of the electro-deposition of AuNPs and self-assembly of GOD.

\section{Results and Discussion}

\subsection{Glucose Biosensor Based on Polypyrrole, Reduced Graphene Oxide, Nanogold and Glucose Oxidase}

The fabrication process of the glucose biosensor based on the electrodeposition-assisted assembled multilayer films of AuNPs and glucose oxidase (AuNPs-GOD) $n$, and the polypyrrole/reduced graphene oxide film (PPy-RGO) modified GCE is shown in Figure 1. PPy and graphene oxide (GO) was first assembled on the bare GCE surface via the electrooxidation of pyrrole to obtain PPy-GO/GCE electrode. Second, AuNPs were electro-reductively deposited on the PPy-GO/GCE electrode surface with the electrochemical reduction of GO immobilized on the PPy-GO/GCE to obtain PPy-RGO-AuNPs/GCE. Third, GOD was self-assembled on PPy-RGO-AuNPs/GCE surface mainly via the interaction between AuNPs and GOD to obtain the PPy-RGO-(AuNPs-GOD) $)_{1} / G C E$ electrode. It has been reported that AuNPs can bind strongly to the biomolecule surface through covalent bonds with the functional groups such as $-\mathrm{NH}_{2}, \mathrm{SH}$, and $-\mathrm{CN}$, and it can provide a suitable microenvironment for biomolecules, such as enzyme and nucleic acids [11,36]. Finally, different layers of AuNPs-GOD multilayer films were built up on the PPy-RGO/GCE surface 
by repeating the process of electrodeposition of AuNPs and self-assembly of GOD to obtain PPy-RGO-(AuNPs-GOD)n/GCE electrode. Herein, this proposed amperometric glucose biosensor, using the PPy-RGO and AuNPs-GOD multilayer films as the sensitive layer, was developed by the eco-friendly electrodeposition and self-assembly without redox reagent, separation procedure, crosslinking or adhesive agents. The possible working mechanisms may involve the following biochemical reactions:

$$
\begin{gathered}
\text { GOD(FAD })+\beta \text {-D-glucose } \rightarrow \text { GOD }\left(\text { FADH }_{2}\right)+\text { D-glucono-1,5-lactone } \\
\text { GOD }\left(\text { FADH }_{2}\right) \rightarrow \text { GOD }(\text { FAD })+2 \mathrm{H}^{+}+2 \mathrm{e}^{-} \\
\text {GOD }\left(\text { FADH }_{2}\right)+\mathrm{O}_{2} \rightarrow \mathrm{GOD}(\mathrm{FAD})+\mathrm{H}_{2} \mathrm{O}_{2} \\
\mathrm{H}_{2} \mathrm{O}_{2} \rightarrow \mathrm{O}_{2}+2 \mathrm{H}^{+}+2 \mathrm{e}^{-}
\end{gathered}
$$

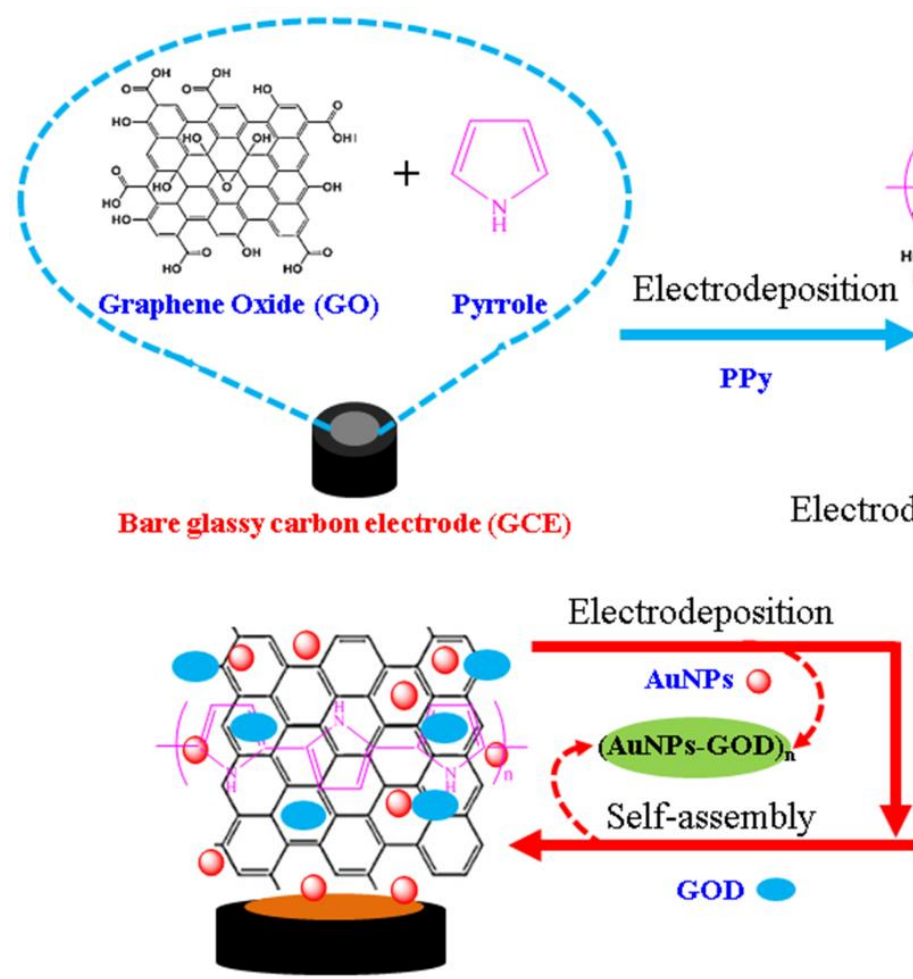

PPy-RGO-(AuNPs-GOD) $)_{\mathrm{n}} / \mathrm{GCE}$

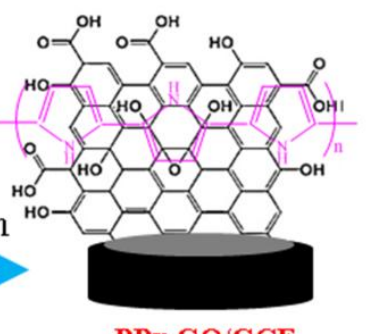

PPy-GO/GCE

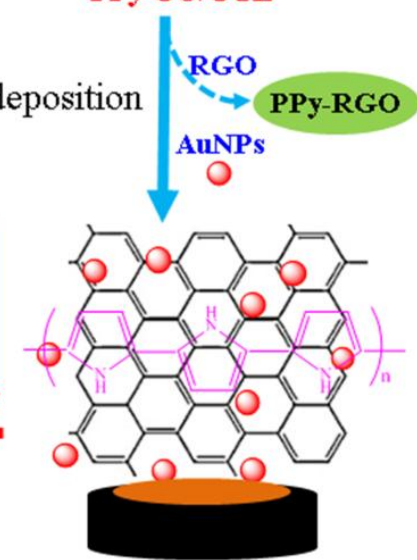

PPy-RGO-AuNPs/GCE

Figure 1. Schematic illustration of a glucose biosensor using the polypyrrole and reduced graphene oxide (PPy-RGO), and gold nanoparticles and glucose oxidase (AuNPs-GOD) multilayer films as the sensitive layer fabricated by the electrodeposition and self-assembly.

When GOD (FAD) catalyzes glucose oxidation, GOD catalyzes glucose to form gluconolactone, and GOD itself is reduced to GOD $\left(\mathrm{FADH}_{2}\right)$. Then, GOD $\left(\mathrm{FADH}{ }_{2}\right)$ is oxidized to GOD (FAD), which can be achieved in two ways: by oxygen re-oxidation back to GOD (FAD) and producing hydrogen peroxide $\left(\mathrm{H}_{2} \mathrm{O}_{2}\right)$ in the process (first generation biosensors), or via direct electron transfer (DET) between $\mathrm{FADH}_{2}$ and electrodes (third generation biosensors) [37,38]. Thus, either the electroactivity of $\mathrm{H}_{2} \mathrm{O}_{2}$ or the direct response current of $\mathrm{FADH}_{2}$ can be used as a measure of glucose in this study.

The electrochemical procedure for the preparation of polypyrrole, reduced graphene oxide, and AuNPs was prepared using literature research [24], with some changes. Here the electrochemical oxidation and the electrochemically reduction are separately performed to avoid drop casting side effects. The electrochemically oxidation of pyrrole with a potential range of $0 \mathrm{~V}-0.8 \mathrm{~V}$ versus SCE and 
the morphology of PPy-GO film are shown in Figure 2. Cyclic voltammograms (Figure 2A) illustrated the continuous electrochemical oxidation of pyrrole, and PPy-GO presented a typical wrinkled and crumpled shape (Figure 2B). As reported in the literature $[39,40]$, pyrrole can be oxidized at $0.8 \mathrm{~V}$. Higher than $0.8 \mathrm{~V}$ may potentially lead to the formation of overoxidized polypyrrole films with poor adherence at the electrode surface. The electrochemical reduction of $\mathrm{HAuCl}_{4}$ and $\mathrm{GO}$ with a potential range of $-1.5 \mathrm{~V}-0 \mathrm{~V}$ versus SCE, and the morphology of PPy-RGO-AuNPs, are shown in Figure 3. Cyclic voltammograms (Figure 3A) illustrated the continuous electrochemical reduction of $\mathrm{HAuCl}_{4}$ and the surface oxygen groups of GO as well as liberating AuNPs and reduced graphene oxide, which was in agreement with previous reports [21,41]. Clearly, the surface morphological feature of PPy-RGO-AuNPs film (Figure 3B) was remarkably different from the PPy-GO film. Many AuNPs were electrochemically deposited in uniform manner, and only a few AuNPs formed larger clusters. The color of PPy-RGO-AuNPs/GCE was visible through a color change of PPy-GO/GCE from clear black to dark brown. The electrochemical deposition process is a potential method for nanomaterials modified electrodes of various active surfaces without redox reagent and separation procedures [42,43]. Thus, all electrochemically conducting surfaces can be covered by PPy, RGO and AuNPs in uniform manner, which can improve the performance of biosensors.

A

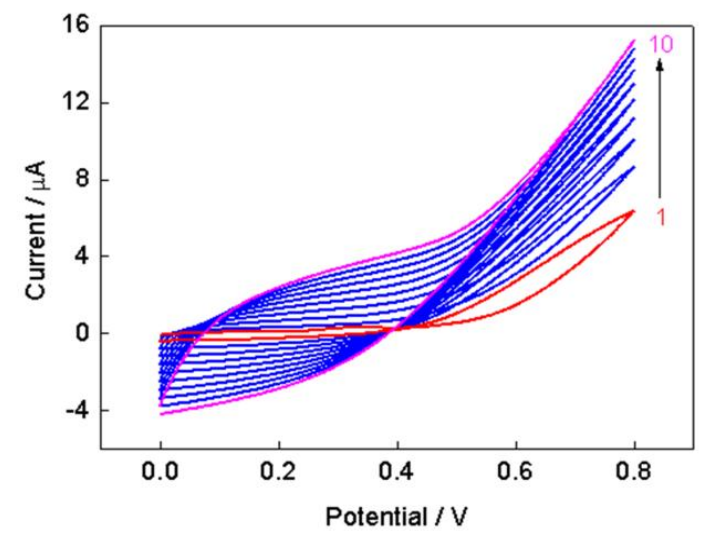

B

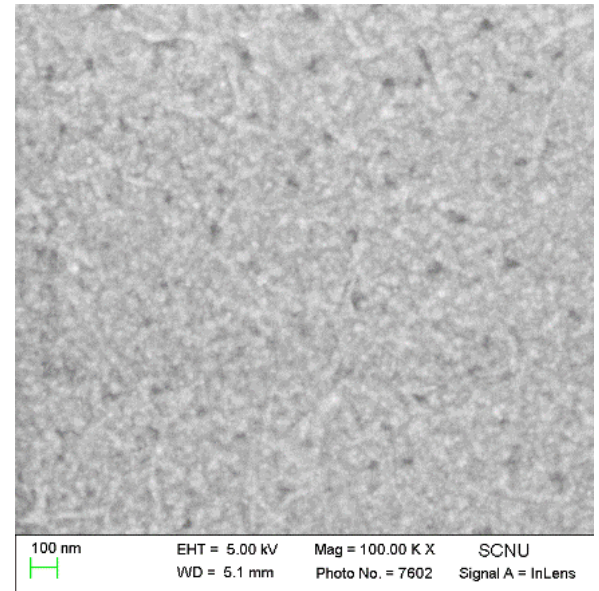

Figure 2. Cyclic voltammograms (CVs) of bare glassy carbon electrode (GCE) in pyrrole/graphene oxide solution for 10 cycles with a scan rate of $25 \mathrm{mV} / \mathrm{s}$ (A) and typical SEM image of polypyrrole (PPy)/graphene oxide (GO) (B).

A

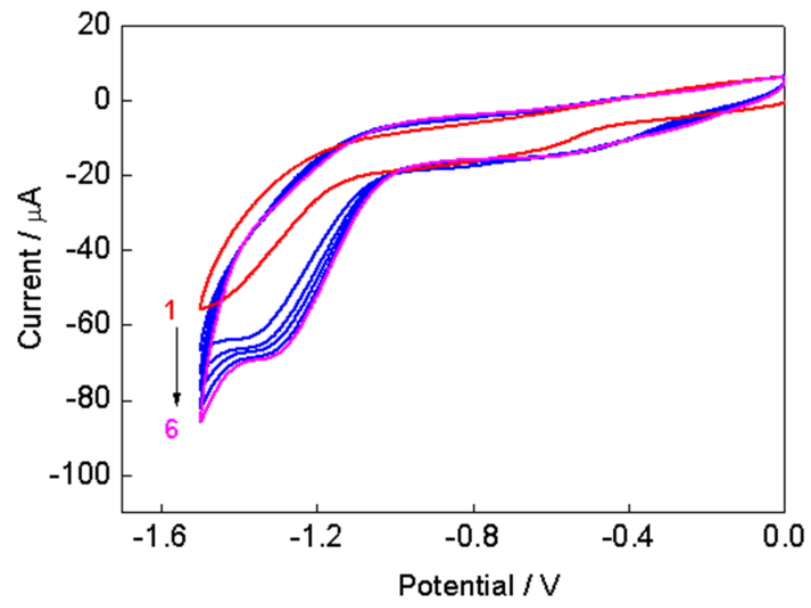

B

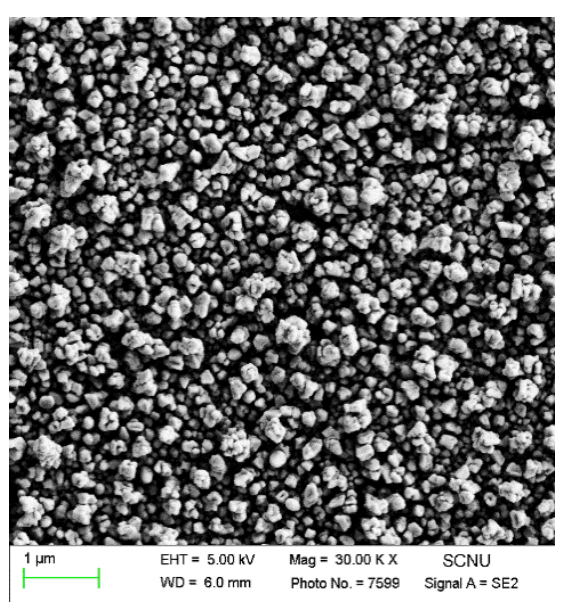

Figure 3. $\mathrm{CVs}$ of PPy-GO/GCE electrode in $\mathrm{HAuCl}_{4}$ aqueous solution for 6 cycles with a scan rate of $25 \mathrm{mV} / \mathrm{s}$ (A), and the typical SEM image of PPy-RGO-AuNPs (B). 


\subsection{The Electrochemical Properties of PPy-RGO-AuNPs Nanocomposite}

The electron transfer properties of various modified electrodes (bare GCE, PPy-GO/GCE, PPy-RGO-AuNPs/GCE, PPy-RGO-(AuNPs-GOD) $)_{1} / \mathrm{GCE}$ ) were studied using cyclic voltammetry in the $\mathrm{KCl}$ solution containing $\left[\mathrm{Fe}(\mathrm{CN})_{6}\right]^{3-/ 4-}$ redox couple with a san rate of $50 \mathrm{mV} / \mathrm{s}$. From the results shown in Figure 4A, the oxidation and reduction peaks were observed at bare GCE, which are related to the electrochemical conversions of Fe (II) to Fe (III) and vice versa. When the GCE electrode was modified with PPy-GO and AuNPs, the peak current of redox had a significant increase, while the peak separation had a decrease compared with bare GCE, confirming the contribution of PPy-GO, RGO and AuNPs. After GOD was adsorbed on PPy-RGO-AuNPs/GCE surface, the resulting PPy-RGO-(AuNPs-GOD) ${ }_{1} /$ GCE electrode decreased peak current and increased peak separation, mainly due to the electrical insulating properties of GOD [44].

A

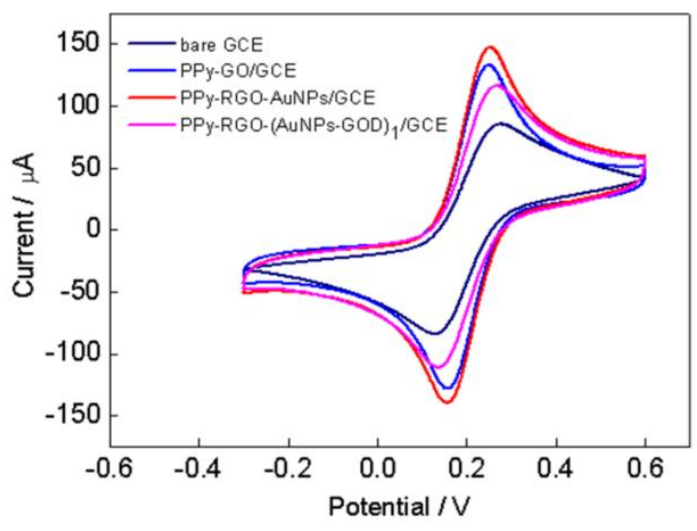

B

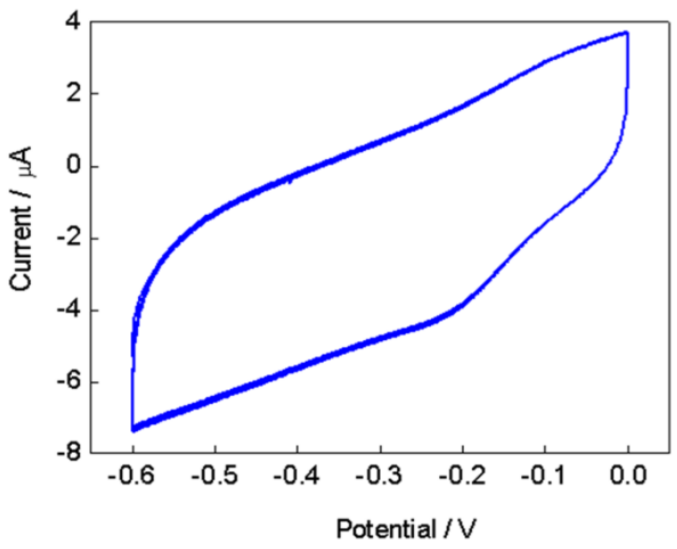

Figure 4. (A) CVs of the electrode at different stages: bare GCE; PPy-GO/GCE; PPy-RGO-AuNPs/GCE; and PPy-RGO-(AuNPs-GOD) 1 /GCE. Supporting electrolyte, $0.1 \mathrm{M} \mathrm{KCl}$ containing $5 \mathrm{mM}$ $\left[\mathrm{Fe}(\mathrm{CN})_{6}\right]^{3-/ 4-}(1: 1)$. (B) CVs of PPy-RGO-(AuNPs-GOD) $1 /$ GCE recorded in $\mathrm{pH} 7.0$ phosphate buffer solutions. Scan rate, $50 \mathrm{mV} / \mathrm{s}$.

Direct electron transfer (DET) of GOD was investigated at a PPy-RGO-(AuNPs-GOD) 1 /GCE electrode in PBS using cyclic voltammetry with a san rate of $50 \mathrm{mV} / \mathrm{s}$. As can be seen from Figure 4B, no GOD redox peak corresponding to the conversion between GOD $\left(\mathrm{FADH}_{2}\right)$ and GOD (FAD) could be observed, indicating that reaction (2)/DET of GOD did not taking place in the present PPy-RGO-AuNPs-GOD-based glucose biosensor. This may be attributed to the fact that the active redox center $\left(\mathrm{FAD} / \mathrm{FADH}_{2}\right)$ of GOD is deeply embedded in a protective protein shell, resulting in the direct electron transfer between GOD and electrode (DET-GOD) being difficult to realize [45]. Although DET is important for the development of electrochemical biosensor, previous studies have reported DET-GOD will lose their native bioactivity owing to the great change in the GOD structure [46,47]. Wooten et al., reported GOD adsorbed on CNT yielded a pair of GOD redox peak, but the anodic peak did not increase in the presence of glucose in an $\mathrm{O}_{2}$-free solution [48]. It has also been demonstrated that DET-GOD is without value in certain mediator-free applications [49]. So the electroactivity of glucose oxidase product $\mathrm{H}_{2} \mathrm{O}_{2}$ (Reactions (3) and (4)) was still chosen as the measure of glucose for PPy-RGO-(AuNPs-GOD) $n$ /GCE in the study. Meanwhile, the result further revealed that our proposed method could maintain the structural integrity of glucose oxidase.

\subsection{Electrochemical Performance of PPy-RGO-(AuNPs-GOD $)_{n} / G C E$ Electrode}

The immobilization amount of GOD on the electrode has a significant effect on the biosensor response. PPy-RGO-(AuNPs-GOD) $n$ /GCE electrodes based on the different layers of AuNPs-GOD multilayer films were fabricated by the combination of the electrodeposited AuNPs and self-assembled 
GOD, and were characterized by cyclic voltammogram in $10 \mathrm{mM}$ glucose. As shown in Figure 5, curves 1-5 displayed cyclic voltammograms of 1-5 layers of AuNPs-GOD multilayer films modified PPy-RGO/GCE electrode, respectively. The response current of the resulting glucose biosensors increased with the increase of the layer number of AuNPs-GOD films. From one to three layers, the current approximately uniformly increased with an increase of more than $10 \mu \mathrm{A}$, and then the current slowly increased after three layers. So the PPy-RGO-(AuNPs-GOD) ${ }_{4} /$ GCE electrode was chosen for further amperometric investigation.

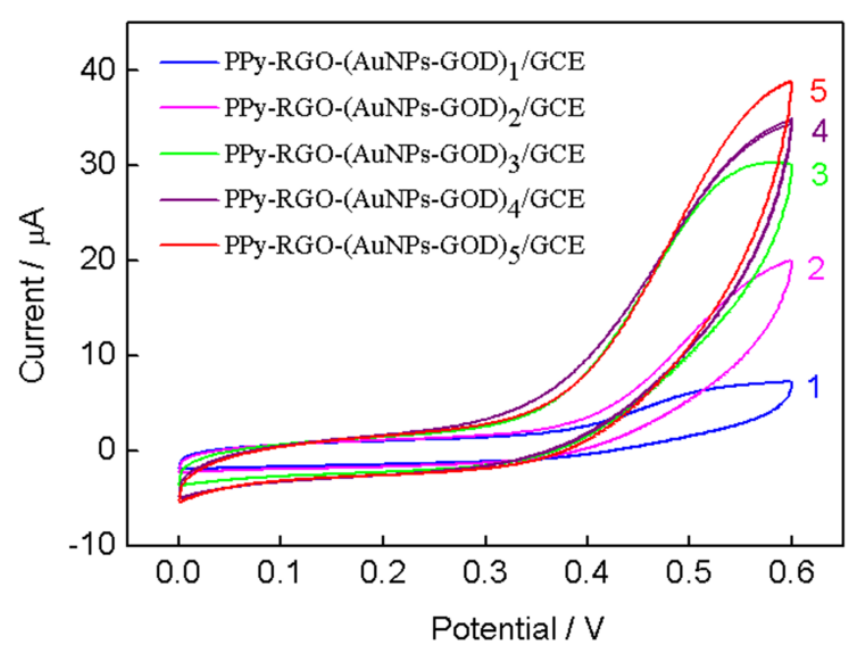

Figure 5. CVs of different layers of AuNPs-GOD multilayer films modified PPy-RGO/GCE in $10 \mathrm{mM}$ glucose. The layer number of multilayer films was indicated on the graph. Scan rate, $50 \mathrm{mV} / \mathrm{S}$.

The applied potential has an important influence over the electrochemical biosensor performance. The effect of applied potential on the response current of PPy-RGO-(AuNPs-GOD) ${ }_{4} /$ GCE electrode was explored by varying the potential from $0.35 \mathrm{~V}$ to $0.55 \mathrm{~V}$ versus SCE in the $4 \mathrm{mM}$ glucose. The obtain amperometric results are shown in Figure 6. The applied potential obviously influenced the response current, and the current increased with the increase of applied potential. By considering the sensitivity and selectivity, an applied potential of $0.5 \mathrm{~V}$ versus SCE was chosen as the working potential.

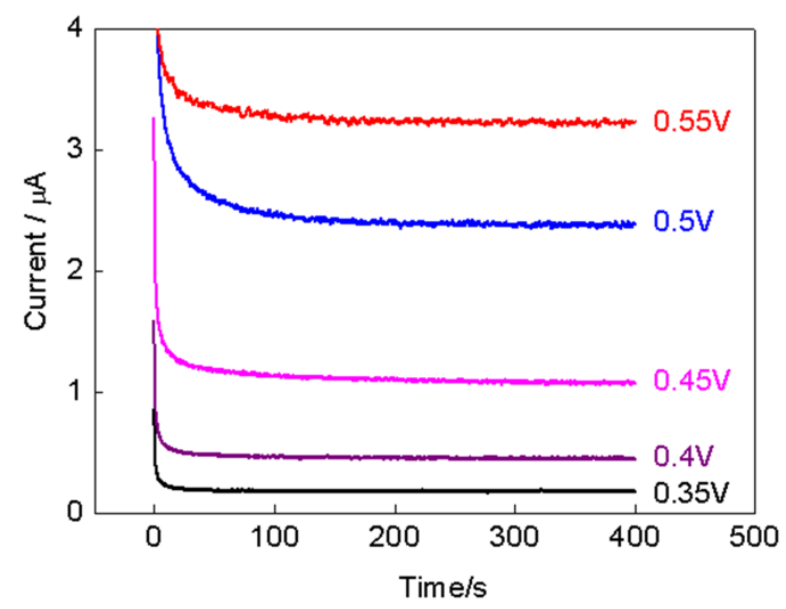

Figure 6. Current-time curves for PPy-RGO-(AuNPs-GOD) ${ }_{4} / \mathrm{GCE}$ in $4 \mathrm{mM}$ glucose at different applied potentials from $0.35 \mathrm{~V}$ to $0.55 \mathrm{~V}$ versus SCE.

Figure 7 shows the typical current-time curve of PPy-RGO-(AuNPs-GOD) $)_{4} / \mathrm{GCE}$ to the successive additions of different concentrations of glucose to PBS at a potential of $0.5 \mathrm{~V}$ versus SCE under gentle magnetic stirring. After recording a baseline current in a stirred solution, $0.2 \mathrm{mM}$ glucose was first 
added five times, followed by the addition of $1 \mathrm{mM}$ glucose 12 times. The glucose concentration is from $0.2 \mathrm{mM}$ to $13 \mathrm{mM}$. As the glucose was added into the stirring buffer solution, the biosensor responded rapidly to the substrates, which achieved $95 \%$ of the steady-state current within 5 seconds. With the increase of glucose concentration, the response current increased. From the corresponding calibration curve (Figure 7 inset) to see, the current and glucose concentration had a linear relationship where glucose concentration ranged from $0.2 \mathrm{mM}$ to $8 \mathrm{mM}\left(R^{2}=0.99\right)$. The linear equation was I $(\mu \mathrm{A})$ $=0.24+0.89 \mathrm{C}(\mathrm{mM})$ with an acceptable relative standard deviation of less than $7 \%$. The sensitivity calculated from the linear calibration was $0.89 \mu \mathrm{A} / \mathrm{mM}$, and a low limit of detection was estimated to be $5.6 \mu \mathrm{M}(\mathrm{S} / \mathrm{N}=3)$.

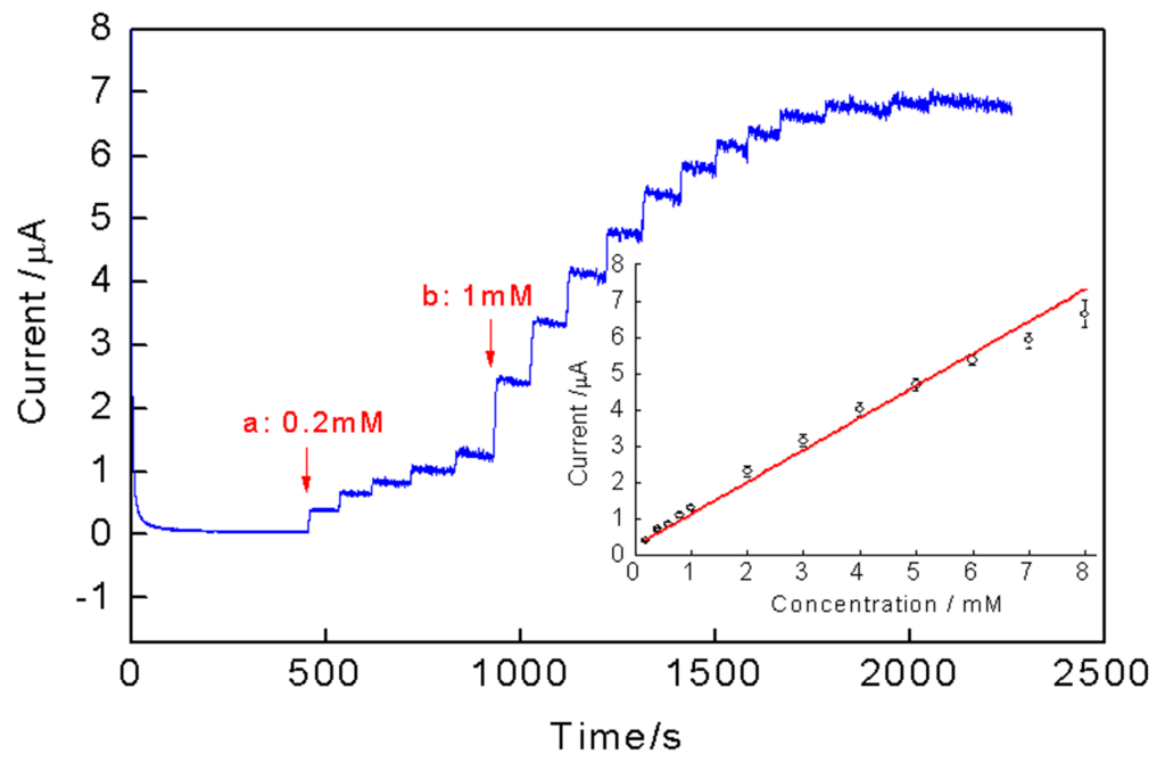

Figure 7. Typical current-time curve recorded at a PPy-RGO-(AuNPs-GOD) 4 /GCE during the addition of different concentration glucose $(0.2 \mathrm{mM}-13 \mathrm{mM})$ at a potential of $0.5 \mathrm{~V}$ versus SCE. The arrows " $a$ " and " $b$ " indicated each increased glucose concentration is $0.2 \mathrm{mM}$ and $1 \mathrm{mM}$, respectively. Inset: the calibration curve of the electrode with glucose concentration ranged from $0.2 \mathrm{mM}$ to $8 \mathrm{mM}$. Error bar $=$ standard deviation $(n=5)$.

The anti-interference ability and stability were also examined. The effects of the presence of three possible interfering substances ascorbic acid (AA), uric acid (UA), and acetaminophen (AC) were examined to evaluate the selectivity of the proposed biosensor. The interfere current obtained for each interfering substance presented at a concentration of $0.1 \mathrm{mM}$ was compared to that of $4 \mathrm{mM}$ glucose. As shown in Figure 8, a large current reached after glucose addition, and no significant response signals were observed upon successive addition of AA, UA, and AC into the system. The small interfering current may be attributed to two aspects: First, negatively charged AuNPs and glucose oxidase can repulse the negatively charged substance. Second, hydrophobic polypyrrole and reduced graphene oxide can repulse the hydrophobic substance. Hence, there may be a repulsive effect between the PPy-RGO-(AuNPs-GOD $)_{4}$ mulitlayer films and interfering substances, and it hinders the diffusion of interfering substances toward the electrode surface. On the contrary, $\mathrm{H}_{2} \mathrm{O}_{2}$ becomes an uncharged hydrophilic small molecule when compared to these interfering substances, and it can easy diffuse to the electrode surface. To assess stability, PPy-RGO-(AuNPs-GOD) 4 /GCE was stored at $4{ }^{\circ} \mathrm{C}$ after use and measured the current response for $4 \mathrm{mM}$ glucose every two days. The electrode retained $90 \%$ of its original current response over two weeks, indicating a good shelf lifetime. This may be attributed to the good stability and biocompatibility of PPy, RGO and AuNPs nanocomposites, and the developed method for PPy, RGO and AuNPs synthesis and GOD immobilization with advantages of the electrodeposition and self-assembly. 


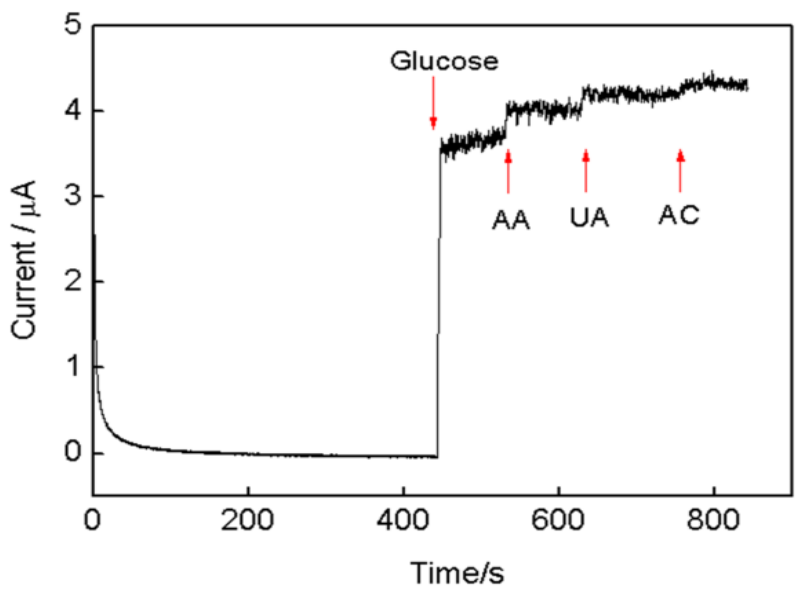

Figure 8. Typical current-time curve recorded at a PPy-RGO-(AuNPs-GOD) $)_{4} /$ GCE during the addition of glucose, ascorbic acid (AA), uric acid (UA), and acetaminophen (AC) at a potential of $0.5 \mathrm{~V}$ versus SCE.

\section{Conclusions}

We have developed a convenient and eco-friendly approach for the facile fabrication of the PPy/RGO/AuNPs and GOD immobilization using the electrodeposition and self-assembly. A corresponding glucose enzymatic biosensor based on the PPy-RGO film and AuNPs-GOD multilayer films was developed without redox reagent, separation procedure, crosslinking and adhesive agents. The proposed method is green and will not result in contamination of the enzyme immobilization matrix/active layer. The as-prepared PPy-RGO-(AuNPs-GOD) $_{4} / G C E$ exhibited a satisfied-performance, which would primarily be attributed to the use of PPy, RGO and AuNPs as GOD immobilization matrix, enzyme catalytic specificity and efficiency, and greatly benefit from the combination of the electrodeposition and self-assembly method. Although the biosensor may still suffer from some drawbacks, such as enzymes stability, the proposed method is sufficiently adaptable and scalable due to the above-noted advantages. The resulting biosensor can serve as a model enzymatic biosensing platform for the development of other electrochemical biosensors, which makes a promising application potential in more complex electrochemical detection systems at various electrode surfaces under environmentally friendly conditions.

Author Contributions: S.H. conceived and designed the experiments; B.W. and S.H. performed the experiments and wrote the paper; Y.X. and Z.C. contributed reagents/materials/analysis tools. All authors reviewed the manuscript and contributed to the discussions.

Funding: This research was funded by the National Natural Science Foundation of China (81371646) and the Natural Science Foundation of Guangdong Province (2017A030313876).

Conflicts of Interest: The authors declare no conflicts of interest.

\section{References}

1. Liu, P.; Zhang, M.; Xie, S.L.; Wang, S.S.; Cheng, W.X.; Cheng, F.L. Non-enzymatic glucose biosensor based on palladium-copper oxide nanocomposites synthesized via galvanic replacement reaction. Sens. Actuators $B$ 2017, 253, 552-558. [CrossRef]

2. Yu, J.; Ni, Y.H.; Zhai, M.H. Highly selective non-enzyme glucose detection based on $\mathrm{Co}-\mathrm{CoO}-\mathrm{Co}_{3} \mathrm{O}_{4}$ nanocomposites prepared via a solution-combustion and subsequent heat-treating route. J. Alloy. Compd. 2017, 723, 904-911. [CrossRef]

3. Gangola, M.P.; Jaiswal, S.; Khedikar, Y.P.; Chibbar, R.N. A reliable and rapid method for soluble sugars and RFO analysis in chickpea using HPAEC-PAD and its comparison with HPLC-RI. Food Chem. 2014, 154, 127-133. [CrossRef] [PubMed] 
4. Ma, J.; Hou, X.F.; Zhang, B.; Wang, Y.; He, L. The analysis of carbohydrates in milk powder by a new“heart-cutting" two-dimensional liquid chromatography method. J. Pharm. Biomed. 2014, 91, 24-31. [CrossRef]

5. Jabariyan, S.; Zanjanchi, M.A.; Arvand, M.; Sohrabnezhad, S. Colorimetric detection of glucose using lanthanum-incorporated MCM-41. Spectrochim. Acta A 2018, 203, 294-300. [CrossRef] [PubMed]

6. Gao, Y.; Wu, Y.T.; Di, J.W. Colorimetric detection of glucose based on gold nanoparticles coupled with silver nanoparticles. Spectrochim. Acta A 2017, 173, 207-212. [CrossRef]

7. Cho, S.J.; Noh, H.B.; Won, M.S.; Cho, C.H.; Kim, K.B.; Shim, Y.B. A selective glucose sensor based on direct oxidation on a bimetal catalyst with a molecular imprinted polymer. Biosens. Bioelectron. 2018, 99, 471-478. [CrossRef]

8. Han, B.k.; Pan, M.X.; Zhou, J.X.; Wang, Y.Y.; Wang, Z.H.; Jiao, J.; Zhang, C.; Chen, Q. Facile synthesis of $\beta$-Lactoglobulin-functionalized reduced graphene oxide and trimetallic PtAuPd nanocomposite for electrochemical sensing. Nanomaterials 2018, 8, 724. [CrossRef]

9. Galant, A.L.; Kaufman, R.C.; Wilson, J.D. Glucose: Detection and analysis. Food Chem. 2015, 188, $149-160$. [CrossRef]

10. Wang, L.Y.; Peng, C.W.; Yang, H.; Miao, L.F.; Xu, L.J.; Wang, L.; Song, Y.H. Ni@carbon nanocomposites/ macroporous carbon for glucose sensor. J. Mater. Sci. 2019, 54, 1654-1664. [CrossRef]

11. Wu, B.Y.; Hou, S.H.; Yin, F.; Zhao, Z.X.; Wang, Y.Y.; Wang, X.S.; Chen, Q. Amperometric glucose biosensor based on multilayer films via layer-by-layer self-assembly of multi-wall carbon nanotubes, gold nanoparticles and glucose oxidase on the Pt electrode. Biosens. Bioelectron. 2007, 22, 2854-2860. [CrossRef] [PubMed]

12. Pakapongpan, S.; Poo-arporn, R.P. Self-assembly of glucose oxidase on reduced graphene oxide-magnetic nanoparticles nanocomposite-based direct electrochemistry for reagentless glucose biosensor. Mater. Sci. Eng. C Mater. 2017, 76, 398-405. [CrossRef] [PubMed]

13. Kallenberg, A.I.; van Rantwijk, F.; Sheldon, R.A. Immobilization of penicillin G acylase: The key to optimum performance. Adv. Synth. Catal. 2005, 347, 905-926. [CrossRef]

14. Shahdost-fard, F.; Roushani, M. Impedimetric detection of trinitrotoluene by using a glassy carbon electrode modified with a gold nanoparticle@fullerene composite and an aptamer-imprinted polydopamine. Microchim. Acta 2017, 184, 3997-4006. [CrossRef]

15. Hou, S.H.; Ou, Z.M.; Chen, Q.; Wu, B.Y. Amperometric acetylcholine biosensor based on self-assembly of gold nanoparticles and acetylcholinesterase on the sol-gel/multi-walled carbon nanotubes/choline oxidase composite-modified platinum electrode. Biosens. Bioelectron. 2012, 33, 44-49. [CrossRef] [PubMed]

16. Eksin, E.; Zor, E.; Erdem, A.; Bingol, H. Electrochemical monitoring of biointeraction by graphene-based material modified pencil graphite electrode. Biosens. Bioelectron. 2017, 92, 207-214. [CrossRef] [PubMed]

17. Şenel, M. Simple method for preparing glucose biosensor based on in-situ polypyrrole cross-linked chitosan/glucose oxidase/gold bionanocomposite film. Mater. Sci. Eng. C Mater. 2015, 48, 287-293. [CrossRef]

18. Shrivastava, S.; Jadon, N.; Jain, R. Next-generation polymer nanocomposite-based electrochemical sensors and biosensors: A review. TrAC Trends Anal. Chem. 2016, 82, 55-67. [CrossRef]

19. Wang, Y.D.; Qing, X.; Zhou, Q.; Zhang, Y.; Liu, Q.Z.; Liu, K.; Wang, W.W.; Li, M.F.; Lu, Z.T.; Chen, Y.L.; et al. The woven fiber organic electrochemical transistors based on polypyrrole nanowires/reduced graphene oxide composites for glucose sensing. Biosens. Bioelectron. 2017, 95, 138-145. [CrossRef]

20. Xue, K.; Xue, S.; Shi, H.; Feng, X.; Xin, H.; Song, W. A novel amperometric glucose biosensor based on ternary gold nanoparticles/polypyrrole/reduced graphene oxide nanocomposit. Sens. Actuators B Chem. 2014, 203, 412-416. [CrossRef]

21. Wang, X.L.; Zhang, X.L. Electrochemical co-reduction synthesis of graphene/nano-gold composites and its application to electrochemical glucose biosensor. Electrochim. Acta 2013, 112, 774-782. [CrossRef]

22. Guo, H.; Wang, X.; Qian, Q.; Wang, F.; Xia, X. A green approach to the synthesis of graphene nanosheets. ACS Nano 2009, 3, 2653-2659. [CrossRef] [PubMed]

23. Zhang, S.; Zheng, J.B. Synthesis of single-crystal $\alpha-\mathrm{MnO}_{2}$ nanotubes-loaded Ag@C core-shell matrix and their application for electrochemical sensing of nonenzymatic hydrogen peroxide. Talanta 2016, 159, 231-237. [CrossRef] [PubMed]

24. Wu, B.Y.; Zhao, N.; Hou, S.H.; Zhang, C. Electrochemical synthesis of polypyrrole, reduced graphene oxide, and gold nanoparticles composite and its application to hydrogen peroxide biosensor. Nanomaterials 2016, 6, 220. [CrossRef] [PubMed] 
25. Liu, C.B.; Wang, K.; Luo, S.L.; Tang, Y.H.; Chen, L.Y. Direct electrodeposition of graphene enabling the one-step synthesis of graphene-metal nanocomposite films. Small 2011, 7, 1203-1206. [CrossRef]

26. Márquez, A.; Jiménez-Jorquera, C.; Domínguez, C.; Muñoz-Berbel, X. Electrodepositable alginate membranes for enzymatic sensors: An amperometric glucose biosensor for whole blood analysis. Biosens. Bioelectron. 2017, 97, 136-142. [CrossRef] [PubMed]

27. Wang, Y.T.; Yu, L.; Zhu, Z.Q.; Zhang, J.; Zhu, J.Z.; Fan, C.H. Improved enzyme immobilization for enhanced bioelectrocatalytic activity of glucose sensor. Sens. Actuators B Chem. 2009, 136, 332-337. [CrossRef]

28. Mai, Y.Y.; Eisenberg, A. Self-assembly of block copolymers. Chem. Soc. Rev. 2012, 41, 5969-5985. [CrossRef]

29. Yu, G.C.; Jie, K.C.; Huang, F. Supramolecular amphiphiles based on Host-Guest molecular recognition motifs. Chem. Rev. 2015, 115, 7240-7303. [CrossRef]

30. Jayakumar, K.; Camarada, M.B.; Dharuman, V.; Ju, H.X.; Dey, R.S.; Wen, Y.P. One-step coelectrodepositionassisted layer-by-layer assembly of gold nanoparticles and reduced graphene oxide and its self-healing three-dimensional nanohybrid for an ultrasensitive DNA sensor. Nanoscale 2018, 10, 2658. [CrossRef]

31. Sun, H.C.; Luo, Q.; Hou, C.X.; Liu, J.Q. Nanostructures based on protein self-assembly: From hierarchical construction to bioinspired materials. Nano Today 2017, 14, 16-41. [CrossRef]

32. Zhang, X.; Chen, H.; Zhang, H. Layer-by-layer assembly: From conventional to unconventional methods. Chem. Commun. 2007, 14, 1395-1405. [CrossRef] [PubMed]

33. Richardson, J.J.; Björnmalm, M.; Caruso, F. Technology-driven layer-by-layer assembly of nanofilms. Science 2015, 348, aaa2491. [CrossRef] [PubMed]

34. Xue, C.M.; Kung, C.C.; Gao, M.; Liu, C.C.; Dai, L.M.; Urbas, A.; Li, Q. Facile fabrication of 3D layer-by-layer graphene-gold nanorod hybrid architecture for hydrogen peroxide based electrochemical biosensor. Sens. Bio-Sens. Res. 2015, 3, 7-11. [CrossRef]

35. Dhawan, S.; Sadanandan, S.; Haridas, V.; Voelckerb, N.H.; Prieto-Simónc, B. Novel peptidylated surfaces for interference-free electrochemical detection of cardiac troponin I. Biosens. Bioelectron. 2018, 99, 486-492. [CrossRef] [PubMed]

36. Si, P.; Kannan, P.; Guo, L.; Son, H.; Kim, D.H. Highly stable and sensitive glucose biosensor based on covalently assembled high density Au nanostructures. Biosens. Bioelectron. 2011, 26, 3845-3851. [CrossRef] [PubMed]

37. Fusco, G.; Göbel, G.; Zanoni, R.; Kornejew, E.; Favero, G.; Mazzei, F.; Lisdat, F. Polymer-supported electron transfer of PQQ-dependent glucose dehydrogenase at carbon nanotubes modified by electropolymerized polythiophene copolymers. Electrochim. Acta 2017, 248, 64-74. [CrossRef]

38. Krishnan, S.K.; Prokhorov, E.; Bahena, D.; Esparza, R.; Meyyappan, M. Chitosan-covered Pd@Pt core-shell nanocubes for direct electron transfer in electrochemical enzymatic glucose biosensor. ACS Omega 2017, 2, 1896-1904. [CrossRef]

39. Astratine, L.; Magner, E.; Cassidy, J.; Betts, A. Electrodeposition and characterisation of copolymers based on pyrrole and 3,4-ethylenedioxythiophene in $\mathrm{BMIM} \mathrm{BF}_{4}$ usinga microcell configuration. Electrochim. Acta 2014, 115, 440-448. [CrossRef]

40. Nowicka, M.; Fau, M.; Rapecki, T.; Donten1, M. Polypyrrole-Au nanoparticles composite as suitable platform for DNA biosensor with electrochemical impedance spectroscopy detection. Electrochimica Acta 2014, 140, 65-71. [CrossRef]

41. Nia, P.; Meng, W.; Lorestani, F.; Mahmoudian, M.; Alias, Y. Electrodeposition of copper oxide/polypyrrole /reduced graphene oxide as a nonenzymatic glucose biosensor. Sens. Actuators B Chem. 2015, 209, 100-108. [CrossRef]

42. Ball, V.; Jun Toh, R.; Voelcker, N.H.; Thissen, H.; Evans, R.A. Electrochemical deposition of aminomalonitrile based films. Colloids Surf. A 2018, 552, 124-129. [CrossRef]

43. German, N.; Ramanavicius, A.; Ramanaviciene, A. Amperometric glucose biosensor based on electrochemically deposited gold nanoparticles covered by polypyrrole. Electroanalysis 2017, 29, 1267-1277. [CrossRef]

44. Wu, B.Y.; Hou, S.H.; Miao, Z.Y.; Zhang, C.; Ji, Y.H. Layer-by-layer self-assembling gold nanorods and glucose oxidase onto carbon nanotubes functionalized sol-gel matrix for an amperometric glucose biosensor. Nanomaterials 2015, 5, 1544-1555. [CrossRef] [PubMed] 
45. Zhao, Y.; Li, W.B.; Pan, L.J.; Zhai, D.Y.; Wang, Y.; Li, L.L.; Cheng, W.; Yin, W.; Wang, X.R.; Xu, J.B.; et al. $\mathrm{ZnO}-$ nanorods/graphene heterostructure: A direct electron transfer glucose biosensor. Sci. Rep. 2016, 6, 32327. [CrossRef] [PubMed]

46. Chi, Q.; Zhang, J.; Dong, S.J.; Wang, E. Direct electrochemistry and surface characterization of glucose oxidase adsorbed on anodized carbon electrodes. Electrochim. Acta 1994, 39, 2431-2436. [CrossRef]

47. Seehuber, A.; Dahint, R. Conformation and activity of glucose oxidase on homogeneously coated and nanostructured surfaces. J. Phys. Chem. B 2013, 117, 6980-6989. [CrossRef]

48. Wooten, M.; Karra, S.; Zhang, M.G.; Gorski, W. Direct electron transfer, sensing, and enzyme activity in the glucose oxidase/carbon nanotubes system. Anal. Chem. 2014, 86, 752-757. [CrossRef]

49. Wang, Y.; Yao, Y.J. Direct electron transfer of glucose oxidase promoted by carbon nanotubes is without value in certain mediator-free applications. Microchim. Acta 2012, 176, 271-277. [CrossRef]

C 2018 by the authors. Licensee MDPI, Basel, Switzerland. This article is an open access article distributed under the terms and conditions of the Creative Commons Attribution (CC BY) license (http://creativecommons.org/licenses/by/4.0/). 